\title{
Definiciones y discursos sobre el caciquismo en los manuales escolares de Historia de España de segundo de bachillerato
}

Recibido: 3 de febrero de 2013 / Aceptado: 17 de marzo de 2013

\author{
Juan Antonio Inarejos Muñoz
}

Resumen

Este artículo es resultado de la investigación "Ciudadanos, propietarios y electores en la construcción del liberalismo español. El caso de las provincias castellano-manchegas, 1854-1868". En él se analizan las nuevas definiciones y discursos del fenómeno del caciquismo decimonónico y se estudia cómo se ha reflejado en los manuales escolares de Historia de España de segundo de bachillerato. Entretanto se desentrañan los tenues avances realizados en la renovación de los contenidos escolares, generalmente anquilosados en tópicos y lugares comunes, y su rigidez a la hora de incorporar novedades historiográficas procedentes del ámbito universitario.

Palabras clave: historia de España, caciquismo, educación, manuales escolares, historiografía.

Abstract

The article presents the results of the research "Ciudadanos, propietarios y electores en la construcción del liberalismo español. El caso de las provincias castellano-manchegas, 1854-1868". The paper analyzes how it was addressed the concept of Spanish caciquismo -bossism - in the Secondary Education textbooks. From the study of these definitions and its treatment in textbooks, it traces the problems that affect the teaching of history, as its stiffness when incorporating new historiography works from the university.

Keywords: History of Spain, bossism, education, textbooks, historiography.

\section{Introducción}

Generalmente el análisis del caciquismo decimonónico ha estado imbuido de una serie de temas y lugares comunes que han coadyuvado a ofrecer una visión cercenada de este complejo fenómeno. Situar su origen en los años de la Restauración canovista, la consideración de la sociedad como desmovilizada, subrogar la dinámica política a las exigencias de las elites económicas o ensalzar la supuesta autonomía de la escena política respecto a los grupos de presión son solo algunos de los más significativos.

En los últimos años, la historiografía ha cuestionado y desmontado muchos de estos temas: se ha

\footnotetext{
* Investigador contratado del programa "Juan de la Cierva" del Grupo de Estudios Internacionales del Instituto de Historia del Consejo Superior de Investigaciones Científicas (Madrid). Licenciado en Historia (premio extraordinario) y Doctor en Historia Contemporánea por la Universidad de Castilla-La Mancha, ha sido becario Postdoctoral en el Centre de Recherches Historiques de L'École des Hautes Études en Sciences Sociales de París entre 2007 y 2009. Ha realizado estancias de investigación en el Departamento de Historia de la Universidad de Santiago de Chile (Chile), en la University of California (San Diego, Estados Unidos), Nice-Sophie (Francia) y SOAS (University of London). Correo electrónic: juaninarejos@hotmail.com.
} 
ubicado su origen a los inicios de la implantación del Estado liberal, ha admitido la diversidad y la complejidad de realidades convergentes, ha subrayado la existencia de interrelaciones entre política y economía, ha desmontado la presunta atonía de la sociedad decimonónica y ha matizado la pretendida omnipotencia estatal-gubernamental por parte de poderes locales ${ }^{1}$. Los nuevos trabajos también han establecido una precisión terminológica del controvertido entramado caciquil. Una realidad bifronte con un diseño político desde arriba, pero cuya configuración social se edificó desde abajo, donde es necesario recomponer en sentido ascendente su construcción social para interpretar posteriormente el diseño político general. Una visión que parte de una concepción poliédrica del poder y del análisis de las relaciones de este poder con el espacio, con instituciones representativas, con partidos políticos, con clientelas o redes de parentesco, y que integra esta nómina de elementos políticos, económicos, sociales, ideológicos y familiares y determina la conexión existente entre ellos (Carasa, 2001). No obstante, ¿hasta qué punto estas nuevas definiciones y discursos sobre el fenómeno caciquil han permeado los manuales escolares de historia de España? ¿Existe una brecha entre los discursos elaborados por el mundo académico universitario y los discursos recogidos en los manuales escolares?

\section{Las nuevas definiciones y discursos del caciquismo decimonónico en España}

Existe un amplio consenso entre las últimas investigaciones centradas en desentrañar los discursos sobre el caciquismo en retrotraer su origen a los primeros pasos del establecimiento del sistema liberal (Adame de Heu, 1997; Peña, Sierra y Zurita, 2010;
Veiga A. 2008). Cabe recordar que ninguno de los gobiernos del periodo bajoisabelino perdió unas elecciones a Cortes, secularmente convocadas desde la atalaya gubernamental. Esta aseveración podría inducir a pensar, como han sugerido distintos estudios para la posterior etapa de la Restauración, en gobiernos todopoderosos que podían confeccionar mayorías parlamentarias sin contestación ni contraprestación alguna. Los resultados arrojados por trabajos recientes han cuestionado la validez de estas premisas a la hora de aplicarlas al estudio del comportamiento electoral isabelino.

El control gubernamental sobre la centralizada administración decimonónica otorgó un instrumento de primer orden a la hora de dirigir el resultado de los comicios. Los diferentes ejecutivos, salvo en aquellas coyunturas marcadas por el afán filolegalista maniataron las diversas fases del proceso electivo. En primer lugar, gracias a la reorganización administrativa destinada a renovar los puestos que otorgaron el control del proceso electoral mediante una selección mediatizada por criterios de carácter político, económico, familiar y o clientelar, cuyo peso recayó preferentemente en la figura del gobernador civil; una de las fases que evidencia con claridad la interconexión entre las consultas electorales municipales y provinciales con las generales. Las amplias atribuciones en materia electoral subrogadas a diputaciones y ayuntamientos explican el interés por controlar ambas instituciones antes y después de los comicios a Cortes, bien para allanar el terreno o para consolidar las plataformas de apoyo trabando los tres niveles del poder liberal. No resulta baladí el interés por contar con la anuencia, entre otros, de alcaldes, fiscales, oficiales de Hacienda o guardas de montes, eslabones esenciales a la hora de ejercer coacción

\footnotetext{
1 Para profundizar en el utillaje documental y teórico empleado en este artículo corto o sintético, suprimido en su mayoría de este estudio-resumen para evitar el fárrago de citas, me remito al trabajo titulado Ciudadanos, propietarios y electores en la construcción del liberalismo español. El caso de las provincias castellano-manchegas, 1854-1868, Madrid, Biblioteca Nueva, 2008; obra que recoge las principales conclusiones de la
} tesis doctoral homónima. 
económica sobre los electores, utilizar las fuerzas de orden público para amedrentar a las oposiciones o controlar las diferentes fases de las votaciones.

No obstante, escapó a los designios gubernamentales la demostrada capacidad de algunos candidatos para ejercer coacción sobre el electorado por medio de los usos políticos de los recursos productivos: tierras, establecimientos industriales o circuitos comerciales. El desmenuzamiento de los censos electorales permite corroborar la variedad de situaciones que albergó el modelo electoral censitario isabelino: grandes terratenientes absentistas, propietarios explotadores directos, medianos y pequeños propietarios como labradores y hortelanos, o cultivadores directos como arrendatarios, colonos o aparceros. Esto constituye una de las palpables evidencias de la multiplicidad de figuras cobijadas bajo el común paraguas de la propiedad.

Esta realidad permite derribar ciertas interpretaciones que han inducido a minusvalorar la instrumentalización política de la dependencia y la subordinación económica a partir de apriorismos centrados en la supuesta homogeneidad económica de los individuos con derechos políticos de ciudadanía en un régimen de sufragio restringido. Lo que, por otra parte, tampoco excluye que una vez implantado el sufragio universal, verdadero mecanismo de alivio conflictual, la dependencia económica generada por la desigual distribución y explotación de los recursos productivos se revalorizase como medio para obtener la dependencia política.

Por lo tanto, esta capacidad de las elites locales de hacer frente a los deseos ministeriales en el terreno electoral obligó a los sucesivos gobiernos a entablar procesos de negociación con el objetivo de evitar que la influencia moral adquiriese proporciones desmedidas de cara a la opinión pública, la verdadera preocupación de los diferentes ejecutivos, más que la propia injerencia en sí. Son constantes los testimonios que inciden en la escrupulosidad y trascendencia concedida a las formas y la recurrente ambivalencia entre la esfera pública y la privada. De cara al exterior era necesario mantener una supuesta apariencia de moralidad y legalidad que evitase en la medida de lo posible dejar al descubierto lo que en la época era voz pública: el manejo partidista y arbitrario de la administración. Las autoridades gubernamentales estuvieron menos preocupadas por la propia injerencia que por las formas e imagen que esta adoptase de cara a la opinión pública. Cuando las coacciones fueron desproporcionadas y alcanzaron un eco no deseado, el gobierno de turno se apresuró a tomar medidas encaminadas a recubrir de un pseudolegalismo el proceso electoral. Fue recurrente presentar la injerencia ejecutiva en las elecciones como una mera cuestión de moral que, con el objetivo de encubrir una intervención perfectamente institucionalizada - como en realidad ocurría - se lograba interceder en la autonomía y dirección del voto.

Independientemente de las pautas legalistas o intervencionistas que adoptó cada gobierno, la inquietud por las formas que revistiese la influencia moral, su repercusión en la opinión pública y la capacidad de las elites de poder local de hacer frente a los designios gubernamentales evidencian lo inapropiado de adoptar, sin realizar ninguna prevención, la tesis de la omnipotencia estatal y de la predisposición gubernamental al fraude electoral. La secular turbación por evitar que la injerencia no adquiriese tintes desmesurados de cara al exterior constituyó una de las constantes en las elecciones desarrolladas en un clima de legalidad, pero también en aquellas singularizadas por unos altos índices de fraude.

Los gobiernos, aun conscientes de su carácter resolutivo, evitaron en la medida de lo posible recurrir al fraude. Esta estrategia también deja entrever otra de las claves explicativas del proceso electoral: la negociación previa entablada entre el poder ejecutivo y las elites de poder local con el objetivo de confeccionar y consensuar las candidaturas. La mera acreditación de la existencia de un proceso negocia- 
dor previo ya revela lo inadecuado de considerar al gobierno y su aparato administrativo como una máquina omnipotente de configurar mayorías parlamentarias.

El proceso negociador anterior constituye uno de los pilares que sustentan las conclusiones resultantes del análisis del comportamiento electoral de la segunda etapa del reinado isabelino: la minoritaria presencia de candidatos cuneros y, por extensión, la capacidad de las elites locales para hacer frente o negociar desde una posición de fuerza con el poder central. Entendemos por cunero no exclusivamente al representante procedente $u$ oriundo de otra circunscripción provincial, sino aquel que además de llegar impuesto desde el exterior a un distrito no mantuvo ninguna vinculación ideológica, familiar, patrimonial o económica con la provincia con la cual no se identificó y explicitó una lejanía y distanciamiento de sus "intereses". Una amplia definición que permite excluir de los catalogados como cuneros a aquellos diputados que, no obstante su origen foráneo, echaron profundas raíces en los distritos, lazos derivados de la compra de bienes territoriales o de vinculaciones ideológicas y o familiares.

Por eso se derrumba el tema de una España rural dominada por los candidatos cuneros, sus anejas connotaciones de subordinación y desmovilización, pero también de una clase política dominada por la atonía y el desinterés. Cuán lejos de la realidad. Solo un reducido porcentaje de los diputados isabelinos analizados optaron por no participar en los debates y trabajos parlamentarios. La tónica general fue la generalizada intervención -aunque desigual y con diferente horizonte - en comisiones y discusiones legislativas. Tampoco se sostiene la imagen monolítica del diputado cunero como el supuesto corolario de la omnímoda influencia del poder central y de su capacidad para imponerse sobre las aspiraciones locales. Los nombramientos de muchos de estos diputados denotan realidades mucho más complejas y respondieron a motivaciones totalmente diferentes.
Ocurrió con el apoyo que recibieron determinadas personalidades que, gracias a sus privilegiadas relaciones con el gobierno, la administración o las cúpulas de los partidos políticos tuvieron la capacidad de satisfacer ante el poder central las aspiraciones y las reivindicaciones de las elites locales.

La segunda de las conclusiones resultantes es la capacidad de las elites de poder local de hacer frente a los designios gubernamentales, ya apuntada por la mera existencia del proceso de negociación, queda aquilatada con la victoria de algunos candidatos de oposición que obtuvieron la victoria frente al candidato ministerial. Unos datos que autorizan a ensalzar el papel de árbitro que desempeñó el Ejecutivo en las disputas entabladas entre las elites locales por acceder al control de los puestos decisivos de la administración; pero también la trascendencia que desde los gobiernos se concedió al proceso previo de negociación para evitar, no tanto la injerencia ministerial en las consultas, como sí su desmesura y su posible filtración a la opinión pública.

¿Dónde residió el potencial de estas elites para hacer frente o negociar con el poder central desde una posición de fuerza? Inexorablemente, la posesión de los recursos productivos constituyó el primer y más importante de los elementos a destacar, a su vez dominado de forma abrumadora por el principal activo en la España eminentemente agraria y rural de mediados del Ochocientos: la tierra. Así lo corrobora su instrumentalización en el terreno electoral, el propio peso de las actividades productivas en los diferentes censos electorales y el predominio ejercido por los propietarios terratenientes en la caracterización socioprofesional de los diputados a Cortes. Aunque eclipsados por los recursos productivos, los vínculos familiares, los círculos de amistades, los lazos ideológicos o la capacidad para ejercer violencia política - y atemperar el monopolio estatal de la fuerza- desempeñaron un papel fundamental a la hora de trabar sólidas redes caciquiles, en las cuales no faltó el control ejercido sobre algunos de los ór- 
ganos de poder local. Un nutrido abanico de factores que autorizan a matizar la consideración de la centralizada administración como una maquinaria en la cual los designios de la cúpula eran transmitidos de forma mecánica hasta la base.

Una capacidad de presión que tampoco implicó necesariamente esa supuesta debilidad del Estado señalada por algunos autores. Más bien se trató de dos realidades complementarias y convergentes en las más de las ocasiones y enfrentadas en las menos, consecuencia directa de la predominante coincidencia de intereses entre las elites centrales y periféricas. Así lo corrobora el elevado porcentaje de actas electores que no registraron protestas entre 1854 a1868 y la minoritaria presencia de candidatos de oposición que finalmente resultaron electos, datos que, lejos de revelar una inexistente omnipotencia estatal derivada de la exclusiva utilización de métodos coactivos, evidencian su interacción con procesos de negociación y de consenso. Caciquismo gubernamental, desplegado por las elites de poder central y en absoluto entendido como un compartimento estanco, a partir de su capacidad de ejercer, por ejemplo, coacción económica o la imposibilidad en otros casos de hacer llegar sus designios hasta el último eslabón del engranaje administrativo; y caciquismo local, ejercido por las elites locales preferentemente a partir de la coacción propiciada por el control directo de los recursos productivos pero también gracias al sometimiento de ciertos resortes de poder administrativo local, de agentes coercitivos o de vínculos familiares; desplegaron un doble y complementario control de las elecciones y se erigió en una pragmática fórmula de encauzar la representación política preludiando los acabados ejemplos desplegados tras la primera experiencia republicana.

\section{Los manuales de texto y los avances de la historiografía, ¿dos compartimentos estancos?}

Uno de los obstáculos que ralentizan el sistema educativo, y por tanto a la enseñanza de la historia, ha sido su escasa flexibilidad a la hora de incorporar novedades historiográficas a los manuales escolares de una forma rápida y eficaz. El tratamiento del tema del caciquismo en los manuales escolares de historia de España de segundo de bachillerato constituye una muestra significativa de los escasos avances realizados en la renovación de unos contenidos generalmente estancados en visiones estereotipadas y problemas superados por la historiografía reciente.

En primer lugar, uno de los más recurrentes constituye situar el origen del sistema caciquil en los años de la Restauración canovista y obviar las irregularidades electorales que tuvieron lugar durante los primeros años del régimen liberal. El manual de Teide reza:

El general O’Donnell repuso la Constitución de 1845. En octubre de 1856, además, el general Narváez volvió a presidir el gobierno. Entre 1856 y 1866 hubo una alternancia en el poder entre el Partido Moderado, dirigido por Narváez, y la Unión Liberal, liderada por O'Donnell. De este modo, los progresistas y los demócratas, pero también los carlistas, quedaban otra vez fuera del juego político. (Alcoberro, Castillo, Cortada, Ferreres y Llorens, 2009, p. 137)

En este manual se obvian los factores que permitieron esa alternancia en el poder de moderados y unionistas, como los recurrentes fraudes electorales presentes ya en esta etapa y en las precedentes, y las estrategias desplegadas por ambos partidos para discriminar a la oposición, como su influencia sobre la sugestionable Isabel II. Una perspectiva similar adopta el manual de Vicens Vives, "Al final del reinado de Isabel II (1856-1868) se alternaron en el gobierno moderados y unionistas" (Fernández, Llorens, Ortega, y Roi, J., 2003, p. 190); sin mención alguna a las prácticas desplegadas por "El gran elector" a la hora de propiciar esa alternancia.

El manual de SM menciona de forma sucinta la "adulteración del sufragio a través de métodos caciquiles" como una de las características de la etapa isabelina. (Bahamonde, y Otero, 2009, p. 108). 
El manual de Akal también retrotrae el despliegue de fraudes electorales a la etapa isabelina: "El sufragio restringido y la manipulación permanente de las elecciones excluían al resto del país" (Hernández, Ayuso y Requero, 2009, p. 210).

No obstante, también deja a un lado los fraudes orquestados durante la etapa de la Unión Liberal y la imposibilidad de la oposición de acceder al poder por vías exclusivamente democráticas:

Fue el gobierno largo de O'Donnell, un periodo de estabilidad favorecido por la ola de prosperidad económica, propiciada por la construcción de ferrocarriles y las grandes inversiones bancarias y bursátiles. La prosperidad también llegó, indirectamente, a las clases populares, lo que explica la ausencia de conflictos graves en aquellos años. Solo una insurrección de jornaleros, en Loja, en 1861, fue contestada por el gobierno con una dura represión. Mientras los progresistas se mantuvieron en la oposición, sin oportunidad alguna de aspirar al gobierno. Demócratas y republicanos, por su parte, quedaban fuera de las Cortes, aunque ganaban fuerza entre las clases populares y los trabajadores fabriles. (Hernández, Ayuso y Requero, 2009, p. 211)

El manual de Santillana sí dedica una especial atención a los comicios de la etapa isabelina, donde certeramente ubica los orígenes del caciquismo, cuya práctica electoral presenta:

[...] sometida a la corrupción y al arreglo... En casi todos los casos la candidatura triunfante fue la del gobierno convocante, cuyo presidente había sido designado por la reina; solo en cinco ocasiones perdió las elecciones el gobierno, y de forma clara solo en 1839. Se puede afirmar, pues, que la maquinaria electoral estuvo siempre al servicio de los intereses del gobierno, gracias a las leyes electorales de 1837 y 1846, que daban mayor poder a los jefes políticos y a los notables locales (llamados luego caciques), que negociaban los resultados a cambio de favores mediante la creación de una densa red clientelar de fidelidades... Desde octubre de 1847 a enero de 1851, el general Narváez volvió a dirigir el gobierno, aumentando su poder. Reorganizó el gobierno de las provincias con la creación de los gobernadores ci- viles, que sustituyeron a los jefes políticos, y perfeccionó el sistema de corrupción electoral, premiando a los que se beneficiaban de este juego y persiguiendo a quienes no lo aceptaban. (Fernández, González, León y Ramírez, 2009, pp. 166-167, 169)

A continuación, el manual de Santillana tampoco pasa por alto la trascendencia de la etapa de gobierno de la Unión Liberal en la evolución de las prácticas caciquiles, y de forma particular de su

ministro de la Gobernación, Posada Herrera, conocido por la oposición progresista como el Gran Elector, dado el grado de perfección que había logrado en la manipulación de las elecciones. Posada sentó las bases de una práctica electoral al servicio de un partido, que iba a dar mayor estabilidad al gobierno y la monarquía. (Fernández, González, León y Ramírez, 2009, p. 175)

El manual de Santillana también proporciona una de las definiciones más completas del sistema de la Restauración, precisamente por el énfasis que se hace en rastrear sus orígenes en las etapas precedentes y la unión de factores económicos, políticos y sociales:

El sistema de la Restauración respondía al modelo de las relaciones de patronazgo, es decir, las relaciones entre el patrón y sus clientes, que recibían favores a cambio de fidelidad. Estas relaciones no eran solo económicas o de clase: las hubo familiares, de negocios, amistades o círculos de influencia social, forjadas ya desde los años del reinado de Isabel II y el Sexenio. De hecho en el Sexenio, Sagasta nunca perdió unas elecciones, prueba de que el sistema ya estaba establecido... En los sistemas parlamentarios sin democracia, como era el de la Restauración, el clientelismo y el populismo fueron dos instrumentos de participación de las masas en la política... Más que del atraso económico, el analfabetismo o la desmovilización política, el caciquismo derivaba directamente de la riqueza como instrumento de dominación y fue un fenómeno social propio de la mentalidad de la época. (Fernández, González, León y Ramírez, 2009, p. 212).

A la hora de explicar el funcionamiento del sistema canovista y el denominado como turno pacífico, no se 
bucea en los antecedentes que habían llevado a tomar la decisión de programar una alternancia política, como habían sido los frecuentes levantamientos ocurridos en las etapas precedentes consecuencia directa de la imposibilidad de acceder al poder por vías legales. En este sentido, el término -o eufemismo- $p a$ cífico es frecuentemente empleado sin ningún tipo de prevención o matización, lo que supone una adjetivación positiva a un periodo convulso y marcado por una muy limitada democratización:

\begin{abstract}
La tercera pieza del sistema canovista era la existencia de dos partidos dinásticos - se llamaban así porque apoyaban a la monarquía de Alfonso XII-que monopolizaba la vida política. Los dos partidos se alternaban en el gobierno del Estado (turno pacífico). (Alcoberro, Castillo, Cortada, Ferreres y Llorens, 2009, p. 155)
\end{abstract}

En esta misma dirección, algunos manuales confunden las causas con las consecuencias del arraigo del sistema caciquil, y precisamente reproducen los mismos argumentos empleados por los defensores del sistema canovista para excluir a la mayoría de la población, como la supuesta atonía y el generalizado analfabetismo:

Todas estas prácticas se apoyaban en un abstencionismo generalizado, de cerca del 80\% del censo. La apatía de la población y el desencanto de las fuerzas de oposición con respecto al sistema explican, en parte, esta tendencia. Por otro lado, esta falsificación sistemática del voto se veía favorecida por el hecho de que casi el 75\% de la población española era analfabeta. (Alcoberro, Castillo, Cortada, Ferreres y Llorens, 2009, p. 137)

Con tasas de analfabetismo altísimas, que alcanzaban el 89\% en el campo, los señores locales decidían con favores y presiones los resultados electorales. (Fernández, Llorens, Ortega, y Roig, 2003, p. 222)

Finalmente, los lugares comunes y visiones estereotipadas también están presentes en las semblanzas biográficas que presentan los manuales sobre las principales figuras políticas de la etapa. Una de las constantes en los manuales escolares de historia de España es la de presentar a estas grandes figuras, dejando a un lado a esas "gentes sin historia" de las que hablaba Galdós, en visiones teleológicas marcadas por relatos y discursos generalmente lineales. Los trazos biográficos de los grandes personajes generalmente son presentados sin discontinuidades ni rupturas que minen su coherencia y orden lineal. Baste recordar el tratamiento - sin mácula- que se hace, por ejemplo, de Cánovas, cuyo perfil biográfico queda exento de cualquier matiz que indicase los perniciosos efectos que tuvieron sus ideas políticas para el sistema democrático:

Antonio Cánovas del Castillo, clave de la Restauración, fue una personalidad polifacética; jurista, historiador, periodista, escritor, conferenciante, orientó su principal actividad hacia la política. Su oficio de historiador contribuyó decisivamente a la gestación de sus ideas políticas. (Fernández, Llorens, Ortega y Roig, 2003, p. 218)

\section{Conclusiones}

El estudio de los discursos y definiciones del caciquismo en los manuales escolares de segundo de bachillerato ha demostrado la necesidad de renovar los temarios y enfoques de unos textos maniatados por lo general en visiones tópicas y tradicionales alejadas de los avances de la historiografía. Para alcanzar esta meta, los conceptos, el vocabulario, los discursos y los contenidos deben ser digeribles y manejables para los alumnos, adaptados a sus capacidades y elaborados por expertos que soporten la responsabilidad de confeccionar buenos materiales escolares que huyan de lugares comunes, aspectos e ideas preconcebidas e incorporen los trabajos realizados en el ámbito académico en los últimos años.

Unos avances que precisamente han incidido en las interacciones entre el conocido como caciquismo gubernamental y el caciquismo local, entendidos como vasos comunicantes y no como rígidos compartimentos estancos. Fueron dos realidades complementarias en la mayoría de los casos y excluyen- 
tes en los menos dados sus intereses convergentes. El análisis de la dinámica electoral isabelina revela la existencia de procesos de negociación y consenso y desautoriza la presunta omnipotencia estatal derivada de la exclusiva utilización de métodos coactivos. Una dialéctica que tampoco supuso la presunta debilidad estatal apuntada por diversos especialistas. El doble y complementario control de las elecciones ejercido por el caciquismo gubernamental y por el caciquismo local se erigió en una ecuación que encauzó la representación política, logró un relativo reconocimiento para los notables dentro del sistema político tras el eclipse revolucionario gaditano y preludió algunas de las claves del ulterior sistema canovista.

Las elites que dirigieron las riendas del Estado liberal aprendieron de las consecuencias derivadas de la exclusión política del liberalismo respetable progresista, orquestada con la inestimable colaboración de Isabel II. La experiencia del Sexenio democrático y la promulgación del amenazante sufragio universal masculino, y la consiguiente relativa pérdida de poder de los notables que tradicionalmente habían ostentado el poder, terminaron por convencer al liberalismo conservador de la necesidad de ampliar la base de apoyo del nuevo régimen turnista que derribó la fugaz experiencia republicana. La capacidad de adaptación de los soportes de poder anclados por los notables y sus partidos permitieron ampliar, dentro de unos estrechos márgenes, su basamento de apoyo y sortear los nuevos escollos (como la promulgación del sufragio universal a finales del siglo XIX). No obstante, la extensión y pervivencia de la corrupción, la incapacidad para realizar aperturas democráticas, el inmovilismo partidista de la Corona o la irrupción de la política y los partidos de masas minaron, junto con otras causas como las consecuencias de las crisis coloniales y o la Gran Guerra, ese relativo consenso que las elites habían alcanzado durante las primeras décadas del siglo XIX que desembocó en la crisis del sistema de partidos. ¿Cuánto tiempo tendrá que pasar para que estas nuevas interpretaciones y dis- cursos sobre el caciquismo impregnen los manuales escolares de historia de España?

\section{Reconocimientos}

El artículo se asocia a la investigación: "Ciudadanos, propietarios y electores en la construcción del liberalismo español. El caso de las provincias castellano-manchegas, 1854-1868", Madrid, Biblioteca Nueva, 2008; obra que recoge las principales conclusiones de la tesis doctoral homónima.

\section{Referencias}

Adame de Heu, W. (1997). Sobre los orígenes del liberalismo histórico consolidado en España (18351840). Sevilla: Universidad de Sevilla.

Alcoberro, A., Castillo, J., Cortada, J., Ferreres, E. y Llorens, J. (Coordinadores) (2009). Historia de España. Ágora. Barcelona: Teide.

Bahamonde, A. y Otero, L. (2009) Historia de Espana $2^{\circ}$ Bachillerato. Madrid: Ediciones SM.

Carasa, P. (2001). De la Burguesía a las Elites, entre la ambigüedad y la renovación conceptual. Ayer, 42, 213-237.

Fernández, A., Llorens Serrano, M., Ortega, R. y Roig, J. (2003). Acervo. Historia. Bachillerato Segundo Curso. Barcelona: Vicens Vives.

Fernández, J., González, J., León, V. y Ramírez, G. (2009). Historia de España $2^{\circ}$ de Bachillerato. Madrid: Santillana Ediciones.

Hernández, J. A., Ayuso, F. y Requero, M. (2009). Historia de España $2^{\circ}$ Bachillerato. Madrid: Akal.

Inarejos, J. (2008). Ciudadanos, propietarios y electores en la construcción del liberalismo español. El caso de las provincias castellano-manchegas, 1854-1868. Madrid: Biblioteca Nueva.

Peña, M., Sierra, M. y Zurita, R. (2010). Elegidos y elegibles. La representación parlamentaria en la cultura del liberalismo. Madrid: Marcial Pons.

Veiga, A. (2008). Historia política y comparación: las elites de Italia y España. En R. Zurina y R. Camu- 
rri (Ed.), Las elites en Italia y en España (18501922) (pp. 245-256). Camurri. Valencia: PUV.

Zurita, R. (2008). Candidatos aceptados, apoyados, impuestos. El gobierno ante las elites locales en la
España liberal. En R. Zurina y R. Camurri (ed.), Las elites en Italia y en España (1850-1922) (pp. 145-165). Valencia: PUV. 